\title{
Author Index for 1993
}

Amiti, B. B., 59

Ang, M. K., 13

Azrak, M., 145

Bagchi, T. P., 31

Banerjee, P., 69

Barnwell, P., 107

Brakspear, S., 107

Chapman, R. J., 39

Church, L. K., 95

Conway, P. P., 1

de Souza, R., 79

de Souza, R., 133

Ekere, N. N., 25

Ekere, N. N., 113

Franklin, A. J., 167

Gay, K. L., 13

Goward, J. M., 179

Gunning, J., 61

Hartwig, A., 175

Hennemann, O.-D., 175

Hinchman, J., 121

Hinchman, J., 95

Hogerton, P. B., 191

Ismail, I., 25

Ismail, I., 113

Jahn, J. R., 1
Keng, Y. C., 79

Khan, M. T, 168

Kumar, M. R., 31

Lee, C.-Y., 121

Lee, C.-Y., 145

Lenkkeri, J., 199

Liu, J., 205

Lo, E. K., 25

Lo, E. K., 113

Mahon, J., 61

Mannan, S. H., 25

Mannan, S. H., 113

Martin-Vega, L. A., 121

Mhaisalkar, S., 79

Ovacik, I. M., 95

Rörgren, R., 169

Rörgren, R., 205

Roth, A. V., 39

Rusanen, O., 199

Tillström, A., 169

Tiong, Y., 79

Uzsoy, R., 95

Uzsoy, R., 121

Whalley, D. C., 85

Whalley, D. C., 179

Williams, D. J., 85

Williams, D. J., 179 